\title{
Prostate cancer-specific survival differences in patients treated by radical prostatectomy versus curative radiotherapy
}

\author{
Julie M. DeGroot, MSc, ${ }^{*}$ Michael D. Brundage, MD, MSc, FRCPC,; Miu Lam, PhD, ; Susan L. Rohland, ; \\ Jeremy Heaton, MD, FACS, FRCSC, William J. Mackillop, MB, FRCR, FRCPC;, D. Robert Siemens, MD, FRCSC,; \\ Patti A. Groome, PhD*
}

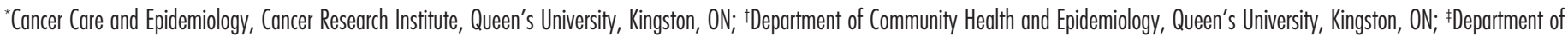
Urology, Queen's University, Kingston, ON

Cite as: Can Urol Assoc J 2013;7(5-6):e299-305. http://dx.doi.org/10.5489/cuaj.11294 Published online May 13, 2013 (early released July 16, 2012).

\section{Abstract}

Objective: We compared the cause-specific survival of patients who received radiotherapy to those who received surgery for cure of their prostate cancer using a number of design and analytic steps to mitigate confounding by indication.

Methods: This was a case-cohort study of 2213 patients in the Ontario Cancer Registry diagnosed between 1990 and 1998 who were either treatment candidates or received curative radiotherapy or surgery. Cases included patients who died of prostate cancer within 10 years. The study population was restricted to those who were candidates for either treatment (radiotherapy or surgery) based on disease severity (low and intermediate risk using the Genitourinary Radiation Oncologists of Canada risk groups). The median follow-up was 51 months. Cause-specific survival was analyzed using Cox-proportional hazards regression with casecohort variance adjustment. Results from intent-to-treat analyses were compared to results by treatment received.

Results: Adjusted hazard ratios for risk of prostate cancer death for radiotherapy compared to surgery for the entire study population were $1.62(95 \% \mathrm{Cl} 1.00-2.61)$ and $2.02(1.19-3.43)$ analyzing by intent-to-treat and treatment received, respectively. Intent-to-treat hazard ratios for the low- and intermediate-risk groups were 0.87 (0.28-2.76) and $1.57(0.95-2.61)$, respectively.

Conclusion: Overall results were driven by the finding in the intermediate-risk group, which indicated that radiotherapy was not as effective as surgery in this group. Confirmation was needed with special attention paid to risk stratification and the impact of more contemporary delivery of these treatment options.

\section{Introduction}

The relative treatment efficacy of surgery and radiotherapy for prostate cancer remains controversial, with conflicting evidence largely from single-institution retrospective studies. Randomized clinical trials on the subject have either closed early due to poor recruitment or were under-powered ${ }^{1-3}$ and one has been heavily criticized. ${ }^{4}$ Observational studies provide information about relative treatment effectiveness in the absence of valid clinical trial evidence, but their design and analysis has to be rigorous to mitigate selection biases. We conducted a population-based observational study that compared the effectiveness of radiotherapy to surgery in localized prostate cancer. We used a case-cohort design to maximize study efficiency. We restricted our study population to patients eligible for either treatment and we used an intent-to-treat approach combined with multivariate regression to control for confounding by indication.

\section{Methods}

We identified all residents of Ontario, Canada who were diagnosed with adenocarcinoma of the prostate between 1990 and 1998 and were either curatively treated with radical prostatectomy or radiotherapy or had an exploratory lymph dissection and, therefore, had likely been treatment candidates. This target population of 17934 patients was defined using information in the Division of Cancer Care and Epidemiology (CCE) database. ${ }^{5}$ Surgical treatment was identified up to 7 months after diagnosis and radiotherapy up to 9 months after with the longer time window chosen to compensate for longer radiotherapy treatment wait times. We included radiotherapy patients whose treatment intent in the electronic record database was curative and who received at least one fraction (200 cGy) of their intended course. All patients received conventional external beam radiotherapy. Our study sample was drawn from this target list and their treatment assignment was subsequently validated using chart data.

In a case-cohort study, the study population consists of a random sample of the target (which we will refer to as the "cohort") plus a sampling or census of cases, defined as patients who have the outcome of interest. This leads to an intentional over-sampling of those with the outcome. ${ }^{6}$ In this design, members of the cohort may also become cases. 
Our cases were defined as those who died of prostate cancer. As with the more familiar case-control design, a case-cohort study is useful in situations where the outcome is rare (such as prostate cancer deaths occurring in curatively-treated patients), but it has the added benefit of being useful when the data are censored. ${ }^{6}$ Another benefit is that the data on the cohort can be used for multiple purposes. This current study was part of a wider effort with some objectives involving the study of a separate case group: those who died of causes other than prostate cancer. Results from those other objectives have been reported separately. ${ }^{7,8} \mathrm{~A}$ stratified (by region of residence) random sample of about $10 \%$ of all patients and $59 \%$ of all cases formed the cohort $(n=1703)$ and case groups $(n=632$, with 122 of selected for both the cohort and cases as per the casecohort design), for a total study population of 2213. Of these, 114 were ineligible or had insufficient treatment information available in the charts (Fig. 1). For this report, we restricted the study population to those with low- to intermediate-risk disease using the Genitourinary Radiation Oncologists of Canada risk groups. ${ }^{9}$ The two groups are commonly thought to be eligible for both treatments. ${ }^{10,11}$ We excluded 210 due to missing disease status. Our final study population was 1065, including 114 cases and 976 cohort members, with 25 selected for both the cohort and cases as per the casecohort design (Fig. 1).

We used the CCE database to identify the treating centres and corresponding charts for data abstraction. Data abstractors used standardized forms and procedures to minimize data collection errors. For a given patient, his cancer centre chart and hospital chart were reviewed whenever possible. All charts were abstracted on site and the data were sent electronically to the coordinating office in Kingston on a weekly basis for logic and missing checks. Findings were communicated to the abstractor who referred back to the original chart to make corrections. If necessary, missing information was sought from secondary hospital, urologist and/ or general practitioner charts. Radiotherapy treatment sheets were photocopied and then abstracted centrally by a research radiation therapist with similar data quality strategies.

During the time period of our study, lymph node dissections were often performed at the start of a prostatectomy and the surgery abandoned if lymph nodes were positive. In an attempt to reduce this surgical selection bias, patients were analyzed by radiotherapy and surgical candidacy using their original treatment intent. The original treatment intent was based on information from the charts using a computerized algorithm that considered the types of treatments offered, the actual treatment, the original treatment plan, the outcome of any lymph node dissection and the reason for any aborted surgery. Patients who had surgery and adjuvant radiotherapy were considered surgical cases $(n<5)$. Our main analysis compared outcomes by treatment intent with a secondary analysis using treatment received. In this case, patients who did not receive radiotherapy or surgery were removed ( $n=11)$, as were radiotherapy patients whose total administered dose was less than 40 Gy $(n=27)$.

We chose death from prostate cancer as our outcome as it is the most definitive measure of the failure of curative treatment. The source of this information was the cause of death code (ICD9 185) as captured in the Ontario Cancer Registry. The registry undergoes periodic death clearances using death certificate data from the Ontario Registrar General which includes this underlying cause of death code. All prostate cancer deaths in this study occurred by December 31,1999 , which was the most current information available when our data collection began and the study population was defined. We calculated time to prostate cancer death from the date of diagnosis. Those alive on December 31, 1999 were censored on that date and those who died of other causes before that date were censored on their date of death.

Gleason score, $T$ category and prostate-specific antigen (PSA) were used to define disease severity. Tumour grade 
Radical prostatectomy vs. radiotherapy in prostate cancer

was used to approximate Gleason score in $15 \%(n=155)$ who did not have a Gleason score. Reviewed pathologic reports were used when available. We analyzed the PSA value closest to the beginning of treatment, but excluded those values taken within 30 days post-biopsy or more than 30 days after initiation of androgen deprivation therapy (ADT). We also included age at diagnosis, ADT and comorbid illnesses, measured by the total Cumulative Illness Rating Scale for Geriatrics (CIRS-G), ${ }^{12,13}$ as covariates.

All statistical analyses were performed using SAS software (version 9.1, SAS Institute, Inc., Cary, NC). We compared age, total CIRS-G, T category, Gleason score and PSA between the radiotherapy and surgery groups in the cases and the cohort. Cox-proportional hazard regression ${ }^{14}$ was performed to compare death from prostate cancer between radiotherapy and surgical patients while controlling for the covariates. The variance estimates in the Cox regression were adjusted for the case-cohort sampling based on the method of Therneau and $\mathrm{Li}^{15}$ and the area-level stratification was accounted for using an approach and SAS macro developed by Langholz and Jiao ${ }^{16}$ with further advice provided by Langholz about incorporating case sampling weights (personal communication, Bryan Langholz, October 2009). We report the unadjusted and fully adjusted results. We also stratified by risk group: low-risk patients were defined as those with a PSA $\leq 10$, Gleason score $\leq 6$ and T category $\leq \mathrm{T} 2 \mathrm{a}$; and intermediate-risk patients were defined as those who were not low risk and had PSA $\leq 20$, Gleason score $\leq 7$ and T category $\leq \mathrm{T} 2 \mathrm{~b} .{ }^{9}$ We tested the consistency of the main effects over time by adding a time-dependent interaction term to our models. We investigated whether competing risk of death from other causes may be explaining our results by conducting separate Cox proportional hazards regression on the cohort and other-cause death case group $(n=319)$ that are part of the larger study as described above. We controlled for the same covariates as in our main analyses in this check of whether the causes of death (prostate cancer vs. other) were independent. ${ }^{17}$

This study was approved by the Research Ethics Boards at Queen's University and many of the hospitals and cancer centres whose charts we abstracted.

\section{Results}

Patients were stratified by the cohort and cases and then by radiotherapy and surgical treatment intent (Table 1 ). Compared to surgical patients, radiotherapy patients were statistically significantly older and had more comorbid illnesses. Their T category distribution also varied with more radiotherapy patients in the $\mathrm{T} 2 \mathrm{~b}$ group. The Gleason score distribution was not statistically significantly different and PSA varied between radiotherapy and surgery patients in the cohort but not across the case groups (Table 1).

\begin{tabular}{|c|c|c|c|c|}
\hline & \multicolumn{2}{|c|}{ Cohort } & \multicolumn{2}{|c|}{ Cases } \\
\hline & $\begin{array}{l}\text { Radiotherapy } \\
\quad(n=518)\end{array}$ & $\begin{array}{l}\text { Surgery } \\
(n=458)\end{array}$ & $\begin{array}{c}\text { Radiotherapy } \\
(\mathrm{n}=78)\end{array}$ & $\begin{array}{c}\text { Surgery } \\
(n=36)\end{array}$ \\
\hline $\begin{array}{l}\text { Average age } \\
\text { (SD) }\end{array}$ & $\begin{array}{l}69.2 \\
(5.6)\end{array}$ & $\begin{array}{l}62.8 \\
(6.1)\end{array}$ & $\begin{array}{l}67.7 \\
(5.7)\end{array}$ & $\begin{array}{l}62.1 \\
(5.8)\end{array}$ \\
\hline$p$ value & \multicolumn{2}{|c|}{$<0.0001$} & \multicolumn{2}{|c|}{$<0.0001$} \\
\hline $\begin{array}{l}\text { Average CIRS-G } \\
\text { (SD) }\end{array}$ & $\begin{array}{c}5.7 \\
(3.7)\end{array}$ & $\begin{array}{c}4.8 \\
(3.3)\end{array}$ & $\begin{array}{c}5.1 \\
(4.1)\end{array}$ & $\begin{array}{c}3.9 \\
(2.8)\end{array}$ \\
\hline$p$ value & \multicolumn{2}{|c|}{$<0.0001$} & \multicolumn{2}{|l|}{0.07} \\
\hline ADT (\%) & 21.6 & 29.0 & 26.9 & 33.3 \\
\hline$p$ value & \multicolumn{2}{|l|}{0.008} & \multicolumn{2}{|l|}{0.48} \\
\hline \multicolumn{5}{|l|}{ T category \% } \\
\hline $\mathrm{T} 1 \mathrm{a} / \mathrm{b}$ & 9.3 & 5.9 & 6.4 & 2.8 \\
\hline $\mathrm{T} 1 \mathrm{c}$ & 20.7 & 37.6 & 12.8 & 25.0 \\
\hline $\mathrm{T} 2 \mathrm{a}$ & 32.8 & 37.3 & 21.8 & 38.9 \\
\hline $\mathrm{T} 2 \mathrm{~b}$ & 37.3 & 19.2 & 59.0 & 33.3 \\
\hline$p$ value & \multicolumn{2}{|c|}{$<0.0001$} & \multicolumn{2}{|l|}{0.03} \\
\hline \multicolumn{5}{|l|}{ Gleason score \% } \\
\hline $2-4$ & 28.2 & 23.6 & 23.1 & 16.7 \\
\hline $5-6$ & 48.5 & 53.3 & 38.5 & 52.8 \\
\hline 7 & 23.4 & 23.1 & 38.5 & 30.6 \\
\hline$p$ value & \multicolumn{2}{|l|}{0.21} & \multicolumn{2}{|l|}{0.35} \\
\hline \multicolumn{5}{|l|}{ PSA \% } \\
\hline$\leq 4$ & 15.8 & 12.5 & 10.3 & 13.9 \\
\hline$>4$ to $\leq 10$ & 43.8 & 57.0 & 46.2 & 38.9 \\
\hline$>10$ to $\leq 20$ & 40.4 & 30.6 & 43.6 & 47.2 \\
\hline$p$ value & \multicolumn{2}{|c|}{0.0002} & \multicolumn{2}{|l|}{0.72} \\
\hline
\end{tabular}

In the cohort, $10 \%$ of radiotherapy patients and $81 \%$ of surgical patients had lymph node dissections, while in the cases these percentages were $19 \%$ and $94 \%$, respectively. Members of the cohort and the radiotherapy cases almost always received their original treatment plan, but only $75 \%$ of the 36 surgical cases did (3 had radiotherapy instead and 6 had no curative treatment).

The median administered dose of radiotherapy for radiotherapy patients was 64 Gy for both the analysis by intent-totreat and the analysis by treatment received. By design, the range was lower in the analysis by intent-to-treat (2-70 Gy), since radiotherapy was abandoned in some patients, compared to the analysis by treatment received (40-70 Gy), where curative radiotherapy was defined as patients having received $\geq 40$ Gy. 271 patients received ADT with 7 patients receiving an orchiectomy, 47 patients receiving adjuvant hormone therapy, and 227 patients receiving neoadjuvant hormone therapy.

In the cohort, 25 patients died of prostate cancer. All were in the cohort and case group due to the sampling method of the case-cohort design. 82 patients died of other causes 


\begin{tabular}{|c|c|c|c|}
\hline & \multicolumn{2}{|c|}{ Intent-to-treat } & \multirow{2}{*}{$\begin{array}{c}\text { Treatment } \\
\text { received } \\
\text { Overall } \\
\text { adjusted* }\end{array}$} \\
\hline & $\begin{array}{c}\text { Overall } \\
\text { unadjusted }\end{array}$ & $\begin{array}{l}\text { Overall } \\
\text { adjusted* }\end{array}$ & \\
\hline Cohort (n) & 976 & 971 & 940 \\
\hline Cases (n) & 114 & 114 & 103 \\
\hline Radiotherapy & $1.91(1.26,2.92)$ & $1.62(1.00,2.61)$ & $2.02(1.19,3.43)$ \\
\hline Age & $1.03(1.00,1.06)$ & $1.01(0.97,1.04)$ & $1.00(0.97,1.04)$ \\
\hline Total CIRS-G & $1.03(0.98,1.10)$ & $1.03(0.97,1.09)$ & $1.03(0.97,1.09)$ \\
\hline ADT & $1.38(0.93,2.07)$ & $1.42(0.94,2.14)$ & $1.32(0.85,2.07)$ \\
\hline \multicolumn{4}{|l|}{ T category } \\
\hline $\mathrm{T} 1 \mathrm{a} / \mathrm{b}$ & $0.32(0.12,0.88)$ & $0.40(0.15,1.06)$ & $0.47(0.19,1.16)$ \\
\hline T1c & $0.41(0.24,0.72)$ & $0.49(0.28,0.86)$ & $0.49(0.26,0.92)$ \\
\hline $\mathrm{T} 2 \mathrm{a}$ & $0.50(0.32,0.77)$ & $0.58(0.36,0.93)$ & $0.56(0.34,0.91)$ \\
\hline $\mathrm{T} 2 \mathrm{~b}$ & 1.0 & 1.0 & 1.0 \\
\hline \multicolumn{4}{|l|}{ Gleason score } \\
\hline $2-4$ & 1.0 & 1.0 & 1.0 \\
\hline $5-6$ & $1.27(0.75,2.13)$ & $1.19(0.72,2.00)$ & $1.06(0.63,1.78)$ \\
\hline 7 & $1.99(1.14,3.47)$ & $1.74(1.00,3.03)$ & $1.73(0.98,3.05)$ \\
\hline \multicolumn{4}{|l|}{ PSA } \\
\hline$\leq 4$ & 1.0 & 1.0 & 1.0 \\
\hline$>4$ to 10 & $1.13(0.62,2.08)$ & $1.09(0.59,2.01)$ & $1.24(0.62,2.47)$ \\
\hline \multirow[t]{2}{*}{$>10$ to $\leq 20$} & $1.70(0.93,3.10)$ & $1.33(0.70,2.53)$ & $1.39(0.69,2.81)$ \\
\hline & $\begin{array}{l}\text { Low risk } \\
\text { unadjusted }\end{array}$ & $\begin{array}{l}\text { Low risk } \\
\text { adjusted* }\end{array}$ & $\begin{array}{l}\text { Low risk } \\
\text { adjusted* }\end{array}$ \\
\hline Cohort (n) & 373 & 371 & 364 \\
\hline Cases (n) & 15 & 15 & 15 \\
\hline \multirow[t]{2}{*}{ Radiotherapy } & $\begin{array}{c}1.56 \\
(0.60,4.04)\end{array}$ & $\begin{array}{c}0.87 \\
(0.28,2.76)\end{array}$ & $\begin{array}{c}0.84 \\
(0.26,2.76)\end{array}$ \\
\hline & $\begin{array}{c}\text { Intermediate } \\
\text { risk unadjusted }\end{array}$ & $\begin{array}{l}\text { Intermediate } \\
\text { risk adjusted* }\end{array}$ & $\begin{array}{l}\text { Intermediate } \\
\text { risk adjusted* }\end{array}$ \\
\hline Cohort (n) & 602 & 599 & 576 \\
\hline Cases (n) & 99 & 99 & 88 \\
\hline Radiotherapy & $\begin{array}{c}1.57 \\
(1.00,2.47)\end{array}$ & $\begin{array}{c}1.57 \\
(0.95,2.61)\end{array}$ & $\begin{array}{c}2.09 \\
(1.18,3.72)\end{array}$ \\
\hline $\begin{array}{l}{ }^{*} \text { Controlling for age } \\
\text { Rating Scale for Ger } \\
\text { antigen. }\end{array}$ & $\begin{array}{l}\text { CIRS-G, ADT, T categ } \\
\text { ratrics; ADT: androgen }\end{array}$ & $\begin{array}{l}\text { Gleason, PSA; CIRS } \\
\text { privation therapy; PS }\end{array}$ & $\begin{array}{l}\text { : Cumulative Illness } \\
\text { prostate-specific }\end{array}$ \\
\hline
\end{tabular}

and 869 were alive on December 31, 1999. The median follow-up time for patients in the cohort was 51 months (range: 2 to 120) and the median time to death for cases was 49 months (range: 1 to 112).

Table 2 presents the results of our Cox regression analyses. Across all patients in the study, radiotherapy was statistically significantly associated with worse survival in the intent-totreat analysis with a hazard ratio of $1.62(95 \% \mathrm{Cl} 1.00-2.61)$ after adjustment for age, CIRS-G, ADT, T category, Gleason score and PSA. In contrast, the unadjusted hazard ratio ana- lyzing by treatment received was 2.38 (1.47-3.85) while the adjusted hazard ratio was 2.02 (1.19-3.43). In the low-risk group, we did not detect a difference in prostate cancer survival between the treatment groups with an adjusted hazard ratio of $0.87(0.28,2.76)$ analyzing by intent-to-treat and 0.84 $(0.26-2.76)$ in the treatment received analysis (Table 2). The intent-to-treat hazard ratios for the intermediate-risk group did not change; the adjustment and unadjusted result was marginally statistically significant: hazard ratio of 1.57 (1.00-2.47). Here, the treatment received result is much further from the null value of 1 , indicating uncontrolled confounding by indication when the original treatment intent is not considered.

We conducted sensitivity analyses on the treatment received results by restricting the radiotherapy subset to those who received a dose of at least 50 Gy ( $\mathrm{n}$ excluded $=89$ ). Those results were similar to the intent-to-treat findings: the adjusted hazard ratio for death from prostate cancer in the $\geq 50$ Gy radiotherapy group was $1.47(95 \% \mathrm{Cl}$ $0.85-2.56)$ with an intermediate-risk group result of 1.66 $(0.90,3.08)$ and a low-risk group result of $0.80(0.26,2.49)$.

We added a time-dependent interaction effect with the radiotherapy indicator to assess the consistency of our main findings (overall, low and high risk intent to treat results) over time. In all three instances, patients who had radiotherapy were only at increased risk of dying from prostate cancer after 3 to 5 years post-diagnosis with the time-dependent interaction being of similar magnitude in each case: across all patients, the coefficient was 0.19 ; for the low-risk group it was 0.16 and for the intermediate risk group it was 0.19 . The radiotherapy patients did not experience a statistically significantly higher risk of other-cause death overall or separately in the low- and high-risk groups (Table 3).

\section{Discussion}

We restricted our study population to patients with lowand intermediate-risk disease who are typically considered candidates for either surgery or radiotherapy. We used an intent-to-treat approach to reduce the confounding by indication that occurs when relative treatment effectiveness is assessed in an observational setting and we used multivariate analysis to control for known confounders. We observed worse cause-specific survival in the radiotherapy patients although our result was marginally significant $\left(\mathrm{HR}_{\mathrm{adj}} 1.62\right.$, $95 \% \mathrm{Cl} 1.00-2.61$ ). When we stratified by risk group, we observed no evidence of worse survival after radiotherapy in the low-risk group $\left(\mathrm{HR}_{\text {adj }} 0.87,95 \% \mathrm{Cl} 0.28-2.76\right)$, and our overall result was determined by the intermediate-risk group $\left(\mathrm{HR}_{\text {adj }} 1.57,95 \% \mathrm{Cl} 0.95-2.61\right)$. Of note, the crude hazard ratio in the intermediate group was identical to the adjusted and achieved marginal statistical significance. Our power to detect a $60 \%$ increase in risk (had it been observed) in the low-risk group was extremely low at $15 \% .{ }^{18}$ Restriction 


\begin{tabular}{|c|c|c|c|}
\hline \multicolumn{4}{|c|}{$\begin{array}{l}\text { Table 3. Hazard ratios for death from causes other than } \\
\text { prostate cancer using intent to treat and treatment } \\
\text { received across all patients and stratified by risk status: } \\
\text { radiotherapy compared to surgery (with } 95 \% \text { confidence } \\
\text { intervals) }\end{array}$} \\
\hline & & Intent-to-treat & $\begin{array}{l}\text { Treatment } \\
\text { received }\end{array}$ \\
\hline & & Adjusted* & Adjusted* \\
\hline \multirow[t]{4}{*}{ Overall } & Cohort (n) & 970 & 940 \\
\hline & Cases (n) & 318 & 308 \\
\hline & Radiotherapy & 1.21 & 1.23 \\
\hline & & $(0.92,1.60)$ & $(0.93,1.63)$ \\
\hline \multirow[t]{4}{*}{ Low risk } & Cohort (n) & 371 & 364 \\
\hline & Cases (n) & 107 & 104 \\
\hline & Radiotherapy & 1.31 & 1.22 \\
\hline & & $(0.82,2.09)$ & $(0.76,1.96)$ \\
\hline \multirow[t]{4}{*}{ Intermediate risk } & Cohort (n) & 599 & 576 \\
\hline & Cases (n) & 211 & 204 \\
\hline & Radiotherapy & 1.11 & 1.19 \\
\hline & & $(0.79,1.56)$ & $(0.83,1.69)$ \\
\hline \multicolumn{4}{|c|}{$\begin{array}{l}{ }^{*} \text { Controlling for age, CIRS-G, ADT, T category, Gleason, PSA; CIRS-G: Cumulative Illness } \\
\text { Rating Scale for Geriatrics; ADT: androgen deprivation therapy; PSA: prostate-specific } \\
\text { antigen. }\end{array}$} \\
\hline
\end{tabular}

to low- and intermediate-risk patients greatly reduced the number of cases from the parent study (and therefore study power) as $75 \%$ had high-risk disease. The collection of population-based stage data that is now occurring across Canada will allow future studies on this question to better target relevant patients.

We investigated whether the competing risk of death from comorbid illnesses could explain our findings. None of these results were statistically significant but the finding in the low-risk group, indicating a possible $31 \%$ increased risk of other-cause death compared to the surgery group, may be due to an imbalance between the radiotherapy and surgery groups on the risk of death from other causes that was not controlled for by our inclusion of the CIRS-G comorbidity score. We were unable to combine the two case groups (prostate cancer deaths and other cause deaths) to perform an overall survival analysis because of differing sampling fractions in the two case groups.

Randomized trial evidence of the relative treatment effectiveness of radiotherapy compared to surgery will be available after 2013 from the ProtecT trial that is being conducted in the United Kingdom. ${ }^{19}$ We are aware of one published randomized trial conducted in Japan that compared surgery plus endocrine therapy to radiotherapy plus endocrine therapy in locally advanced prostate cancer which was inconclusive due to insufficient study power. ${ }^{3}$ Another trial comparing radical prostatectomy to radiotherapy in the United States found surgery to be superior to radiotherapy, however it has been criticized for many methodological shortcomings. ${ }^{1,2,4}$ Other attempts have been unsuccessful due to poor recruitment. ${ }^{1}$ Previously reported observational studies on this topic have shown mixed results, but none took all the steps that we did to minimize confounding by indication.

Two reports are most similar to our study regarding outcome and timeframe. ${ }^{20,21}$ Albertsen and colleagues observed a cause-specific survival decrement for radiotherapy with a hazard ratio of 2.2 (1.6-3.1), while analyzing by intent-totreat but including high-risk patients. Those patients were treated between 1990 and 1992. ${ }^{20}$ Merglen and colleagues similarly showed a 10 -year survival decrement for radiotherapy analyzing by treatment received with a hazard ratio of 2.3 (1.2-4.3) in patients treated between 1989 and 1998. ${ }^{21}$ Radiotherapy dose was not reported in these studies but was likely similar to ours given the timeframe.

Several studies have shown no statistically significant differences in biochemical relapse-free survival (bRFS). Potters and colleagues found that the 7-year bRFS hazard ratio for radiotherapy (all treated with $\geq 70 \mathrm{~Gy}$ ) compared to surgery was 1.18 (0.86-1.62), ${ }^{22}$ while Martinez and colleagues found no difference in the 7-year bRFS odds ratio: 0.98 (0.551.74) with radiotherapy doses between $59-70$ Gy. ${ }^{23}$ Vicini and colleagues found no statistically significant differences in bRFS for any subgroup formed and varying approaches to radiotherapy delivery across seven institutions; ${ }^{24}$ and Kupelian and colleagues computed a hazard ratio of 1.01 ( $p=0.96)$ comparing radiotherapy (68-78 Gy) to surgery for difference in bRFS after control for disease severity and other key confounding variables. ${ }^{25} \mathrm{D}^{\prime} \mathrm{Amico}$ and colleagues found no difference in 8-year bRFS for intermediate-risk patients with high volume tumours and high-risk patients, however they did observe higher 8-year bRFS for low-risk patients or intermediate-risk patients with low volume tumours treated surgically compared to the radiotherapy group whose median dose was $66 \mathrm{~Gy} .{ }^{26}$ More recently, Aizer and colleagues observed a benefit from intensity-modulated radiotherapy ( $\geq 72$ Gy) compared to surgery in bRFS, but the result was marginally significant with an adjusted hazard ratio of 0.62 $(0.38,1.03) .{ }^{27}$ Zelefsky and colleagues showed more favourable prostate cancer-specific survival for surgery compared to intensity-modulated radiotherapy ( $\geq 81 \mathrm{~Gy}$ ) for localized prostate cancer with a hazard ratio of $0.32(p=0.02)$ with the strongest result observed in patients who were considered at high risk of death from prostate cancer. ${ }^{28}$

Our use of the intent-to-treat approach minimized the bias from under-reporting of pathological positive lymph node status in radiotherapy patients compared to surgical patients, as only $12 \%$ of radiotherapy patients in the cohort received a lymph node dissection compared to $88 \%$ of surgical patients. This approach yielded a hazard ratio that was 0.40 closer to the null than our treatment-received result. Lu-Yao and Yao showed that analyzing by intent-to-treat versus actual treatment received had little effect on 10-year survival rates for patients treated by radiotherapy, but dif- 
fered significantly for surgical patients with survival rates of $83 \%(95 \% \mathrm{Cl} 81-84 \%)$ versus $89 \%(87-91 \%)$, respectively. ${ }^{29}$ A similar pattern can be seen in our study, as nearly all radiotherapy patients actually received radiotherapy whereas only $81 \%$ of surgical patients actually received surgery.

Other strengths of our study include the fact that this study was population based, with subjects accrued from all across Ontario, so our results are not influenced by referral bias and the potentially homogeneous treatment biases that can be present in single-institution studies. Our restriction to low- to intermediate-risk patients is similar to what would occur in a randomized trial where patients must be candidates for both treatment arms. We were able to use detailed information on covariates due to our extensive chart review, which provided more information than is normally available in population-wide analyses that typically use electronic administrative data. Our use of death from prostate cancer as our outcome provides evidence about the definitive endpoint in this disease which is in contrast to many studies that have used the surrogate endpoint of biochemical free relapse which has not been well-validated. ${ }^{30}$ We used a case-cohort design, which is an efficient choice when the outcome is rare because it reduces the data collection effort required in the non-cases; this study included 114 prostate cancer deaths while a similar-sized cohort study would have included only about 25 such deaths.

The main limitation of our study is that it was observational rather than experimental; unmeasured confounders distinguishing those who get radiotherapy from surgery may be biasing our results. This study would have benefitted from consideration of other measures of disease burden that are collected in more recently treated patients, such as number of cores positive, PSA velocity and information about perineural invasion. Also, residual confounding may be present in our control of Gleason scores because: (1) grade was used to approximate the score in $15 \%$ and (2) Gleason score migration toward higher values occurred during the latter part of our study.

Two popular approaches for addressing unmeasured confounding in observational research of intended treatment effects are the use of propensity scores and the instrumental variables approach. Studies that use multivariate analysis and propensity scores in a regression have been shown to frequently produce the same results. ${ }^{31,32}$ We used a propensity score approach to assess whether the treatment effect varied as a patient's indication for radiotherapy increased. These analyses were negative due to limited study power (results not shown). We also investigated the use of the instrumental variables method with the county-level instrument identified using treatment information available on the entire target population of 17 934. The disease risk and comorbidity distributions varied between the instrumental groups thus violating the primary assumption of this approach.
Another important limitation is that there have been big changes in the delivery of the two treatment options since the patients in our study were treated and the use of active surveillance in low-risk patients is a new development. Dose-escalated radiotherapy would likely lead to better outcomes than we observed in that group, ${ }^{33}$ but two recent observational studies have reached opposite conclusions. ${ }^{27,28}$ There is clearly a need to demonstrate that newer radiotherapy treatment approaches have resolved the disease control problems that we, and others, have documented.

Some of the patients may have died from a cause other than prostate cancer. There is evidence of good agreement between death certificate cause of death assignment and information in prostate cancer patient charts, ${ }^{34}$ but those treated with surgery or those diagnosed with other cancers may be more likely to be labeled as having died of a cause other than prostate cancer. ${ }^{35,36}$ Such misattribution, if present in our study, may have decreased the number of cases in the surgical group thus biasing our results toward an increased risk in the radiotherapy group. Lastly, our results apply to prostate cancer deaths that occur within 10 years with a median follow-up time of 4.2 years. Unfortunately, the study design precluded collection of follow-up information after 1999 because cases had to be chosen prior to data collection. Our results may not apply to prostate cancer deaths occurring after this time period if one thinks that the relative effect of radiotherapy to surgery changes over time. However, although its results were not statistically significant, the randomized trial by Akakura and colleagues are interesting. Their trial had a median follow-up of 102 months and the risk ratio derived from 10-year survival figures was the same as we observed: $66.1 \%$ cause-specific survival in the radiotherapy group compared to $83.5 \%$ in the surgical group which translates to a relative risk of 1.60 .

\section{Conclusions}

In this study, radiotherapy and surgery as practiced in the 1990s in Ontario, Canada conferred similar prostate cancer control rates in low-risk patients, but not in those with intermediate risk disease where radiotherapy conferred a 57\% increased risk. Until definitive randomized trial evidence is available, we depend on well-designed observational studies to assess relative treatment effectiveness in this disease. Population-based studies of prostate cancer survival that include patients treated with newer surgical techniques and dose-escalated radiotherapy are needed to determine whether radiotherapy can produce equivalent prostate cancer survival rates to surgery for intermediate-risk patients. Future studies would benefit from using either the casecohort or nested case-control design, perhaps nested within a larger cohort initiative, because prostate cancer deaths in this group are rare. 
Competing interests: None declared.

This paper has been peer-reviewed.

Acknowledgements: We would like to thank Professors Bryan Langholz, Sven Ove Samuelsen and Paul Peng for their thoughtful advice on the case-cohort analysis and Karleen Schulze and Zhi Song for their programming and statistical support during the study design and data collection periods. Dr. Groome is the Canada Research Chair in Cancer Care Evaluation. This research was undertaken, in part, thanks to funding from the Canada Research Chairs Program. We wish to acknowledge the Ontario Cancer Registry and Cancer Care Ontario for providing us with the Ontario registry data used in this study. This research was supported by the Canadian Cancer Society through the National Cancer Institute of Canada.

\section{References}

1. Penson DF. An update on randomized clinical trials in localized and locoregional prostate cancer. Urol Oncol 2005;23:280-8

2. Paulson DF, Lin GH, Hinshaw W, et al. Radical surgery versus radiotherapy for adenocarcinoma of the prostate. J Urol 1982;128:502-4.

3. Akakura K, Suzuki H, Ichikawa T, et al. A randomized trial comparing radical prostatectomy plus endocrine therapy versus external beam radiotherapy plus endocrine therapy for locally advanced prostate cancer: results at median follow-up of 102 months. Jpn I Clin Oncol 2006;36:789-93.

4. Hanks GE. More on the Uro-Oncology Research Group report of radical surgery vs. radiotherapy for adenocarcinoma of the prostate. Int J Radiat Oncol 1988; 14:1053-4.

5. Mackillop WJ, Zhang-Salomons J, Groome PA, et al. Socioeconomic status and cancer survival in Ontario. J Clin Oncol 1997;15:1680-89.

6. Prentice RL. A case-cohort design for epidemiologic cohort studies and disease prevention trials. Biometrika 1986;73:1-11.

7. Chan EOM, Groome PA, Siemens DR. Validation of quality indicators for radical prostatectomy. Int J Cancer 2008;123:2651-7.

8. Groome PA, Rohland SL, Siemens DR, et al. Co-morbid illness effects on survival after curative treatment for prostate cancer. Cancer 2011;117:3943-52.

9. Lukka H, Warde P, Pickles T, et al. Controversies in prostate cancer radiotherapy: consensus development. Can J Urol 2001:8:1314-22.

10. BC Cancer Agency. Cancer Management Guidelines. 2004.

11. Cancer Care Nova Scotia. Guidelines for the Management of Prostate Cancer. 2006.

12. Linn BS, Linn MW, Gurel LG. Cummulative Illness Rating Scale. J Am Geriatr Soc 1968; 16:622-26.

13. Miller MD, Paradis CF, Houck PR, et al. Rating chronic medical illness burden in geropsychiatric practice and research: application of the Cumulative Illness Rating Scale. Psychiat Res 1992;41:237-48.

14. Cox D. Regression models and life-tables (with discussion). J R Stat Soc B 1972;34:187-220.

15. Therneau TM, Li H. Computing the Cox model for case cohort designs. Lifetime Data Anal 1999:5:99-112.

16. Langholz B, Jiao J. Computational methods for case-cohort studies. Comput Stat Data An 2007;51:373748.

17. Lau B, Cole SR, Gange SJ. Competing risk regression models for epidemiologic data. Am J Epidemiol 2009;170:244-56.
18. Kim MY, Xue X, Du Y. Approaches for calculating power for case-cohort studies. Biometrics 2006;62:92933.

19. The Protect trial - Evaluating the effectiveness of treatment for clinically localized prostate cancer ISRCTN20141297 (Accessed 9 July 2012).

20. Albertsen PC, Hanley JA, Penson DF, et al. 13-year outcomes following treatment for clinically localized prostate cancer in a population based cohort. J Urol 2007;177:932-6.

21. Merglen A, Schmidlin F, Fioretta G, et al. Short- and long-term mortality with localized prostate cancer. Arch Intern Med 2007;167:1944-50.

22. Potters L, Klein EA, Kattan MW, et al. Monotherapy for stage T1-T2 prostate cancer: radical prostatectomy, external beam radiotherapy, or permanent seed implantation. Radiother Oncol 2004;71:29-33.

23. Martinez AA, Gonzalez JA, Chung AK, et al. A comparison of external beam radiation therapy versus radical prostatectomy for patients with low risk prostate carcinoma diagnosed, staged, and treated at a single institution. Cancer 2000;88:425-32.

24. Vicini FA, Martinez A, Hanks $G$, et al. An interinstitutional and interspecialty comparison of treatment outcome data for patients with prostate carcinoma based on predefined prognostic categories and minimum follow-up. Cancer 2002;95:2126-35.

25. Kupelian PA, Elshaikh M, Reddy CA, et al. Comparison of the efficacy of local therapies for localized prostate cancer in the prostate-specific antigen era: a large single-institution experience with radical prostatectomy and external-beam radiotherapy. J Clin Oncol 2002;20:3376-85.

26. D'Amico AV, Whittington R, Malkowicz SB, et al. Biochemical outcome after radical prostatectomy or external beam radiation therapy for patients with clinically localized prostate carcinoma in the prostate specific antigen era. Cancer 2002;95:281-6.

27. Aizer $A A, Y_{U} J B$, Colberg JW, et al. Radical prostatectomy vs. intensity-modulated radiation therapy in the management of localized prostate adenocarcinoma. Radiother Oncol 2009;93:185-91.

28. Zelefsky MJ, Eastham JA, Cronin AM, et al. Metastasis after radical prostatectomy or external beam radiotherapy for patients with clinically localized prostate cancer: a comparison of clinical cohorts adjusted for case mix. J Clin Oncol 2010;28:1508-13.

29. Lu-Yao GL, Yao SL. Population-based study of long-term survival in patients with clinically localised prostate cancer. Lancet 1997;349:906-10.

30. Collette L, Burzykowski TZ, Schroder FH. Prostate-specific antigen (PSA) alone is not an appropriate surrogate marker of long-term therapeutic benefit in prostate cancer trials. Eur J Cancer 2006;42:1344-50.

31. Shah BR, Laupacis A, Hux JE, et al. Propensity score methods gave similar results to traditional regression modeling in observational studies: a systematic review. I Clin Epidemiol 2005;58:550-9.

32. Sturmer $\mathrm{T}$, Joshi $M$, Glynn RJ, et al. A review of the application of propensity score methods vielded increasing use, advantages in specific settings, but not substantially different estimates compared with conventional multivariable methods. J Clin Epidemiol 2006:59:437-47.

33. Zietman AL, DeSilvio ML, Slater JD, et al. Comparison of conventional-dose vs high-dose conformal radiation therapy in clinically localized adenocarcinoma of the prostate: a randomized controlled trial. JAMA 2005;294:1233-9.

34. Penson DF, Albertsen PC, Nelson PS, et al. Determining cause of death in prostate cancer: are death certificates valid? J Natl Cancer Inst 2001;93:1822-3.

35. Newschaffer CJ, Otani K, McDonald MK, et al. Causes of death in elderly prostate cancer patients and in a comparison nonprostate cancer cohort. J Natl Cancer Inst 2000;92:613-21.

36. Albertsen $\mathrm{PC}$, Walters S, Hanley JA. A comparison of cause of death determination in men previously diagnosed with prostate cancer who died in 1985 or 1995. J Urol 2000;163:519-23.

Correspondence: Dr. Patti A. Groome, Cancer Research Institute, Division of Cancer Care and Epidemiology, 10 Stuart St., Level 2, Kingston, ON K7L 3N6; fax: 613-533-6794; patti.groome@krcc.on.ca 